\section{- OPEN ACCESS}

\title{
Comparing the characteristics of users of an online service for STI self-sampling with clinic service users: a cross-sectional analysis
}

\author{
Sharmani Barnard, ${ }^{1}$ Caroline Free, ${ }^{2}$ Ioannis Bakolis, ${ }^{3}$ Katy M E Turner, ${ }^{4}$ \\ Katharine J Looker, ${ }^{5}$ Paula Baraitser ${ }^{1}$
}

- Additional material is published online only. To view please visit the journal online (http://dx.doi.org/10.1136/ sextrans-2017-053302).

${ }^{1}$ School of Population Health and Environmental Sciences, Centre for Global Health and Health Partnerships, King's College London, London, UK ${ }^{2}$ Faculty of Epidemiology, London School of Hygiene and Tropical Medicine, London, UK ${ }^{3}$ Department of Biostatistics and Health Services Research, Institute of Psychiatry, Psychology and Neuroscience, King's College London, London, UK

${ }^{4}$ Department of Veterinary Sciences, Bristol Vet School, University of Bristol, Bath, UK ${ }^{5}$ Department of Population Health Sciences, Bristol Medical School, University of Bristol, Bristol, UK

\section{Correspondence to} Ms Sharmani Barnard, School of Population Health and Environmental Sciences, Centre for Global Health and Health Partnerships, King's College London, London, SE5 9RJ, UK: sharmani.barnard@kcl.ac.uk

Received 6 June 2017 Revised 6 December 2017 Accepted 3 January 2018 Published Online First 7 February 2018

\begin{abstract}
Objectives Online services for self-sampling at home could improve access to STI testing; however, little is known about those using this new modality of care. This study describes the characteristics of users of online services and compares them with users of clinic services. Methods We conducted a cross-sectional analysis of routinely collected data on STI testing activity from online and clinic sexual health services in Lambeth and Southwark between 1January 2016 and 31March 2016. Activity was included for chlamydia, gonorrhoea, HIV and syphilis testing for residents of the boroughs aged 16 years and older. Logistic regression models were used to explore potential associations between type of service use with age group, gender, ethnic group, sexual orientation, positivity and Index of Multiple Deprivation (IMD) quintiles. We used the same methods to explore potential associations between return of complete samples for testing with age group, gender, ethnic group, sexual orientation and IMD quintiles among online users. Results $6456 \mathrm{STI}$ tests were carried out by residents in the boroughs. Of these, 3582 (55.5\%) were performed using clinic services and 2874 (44.5\%) using the online service. In multivariate analysis, online users were more likely than clinic users to be aged between 20 and 30 years, female, white British, homosexual or bisexual, test negative for chlamydia or gonorrhoea and live in less deprived areas. Of the individuals that ordered a kit from the online service, $72.5 \%$ returned sufficient samples. In multivariate analysis, returners were more likely than non-returners to be aged $>20$ years and white British. Conclusion Nearly half (44.5\%) of all basic STI testing was done online, although the characteristics of users of clinic and online services differed and positivity rates for those using the online service for testing were lower. Clinics remain an important point of access for some groups.
\end{abstract}

\section{INTRODUCTION}

STIs remain an important public health concern in the UK with increasing diagnoses of syphilis and gonorrhoea and high rates of late diagnosis of HIV. ${ }^{12}$ Case identification and treatment is an effective form of preventing onward transmission, and strategies to improve access to diagnostic testing are a priority. ${ }^{34}$ Online services for STI self-sampling at home harness almost ubiquitous access to the internet through mobile technologies among people of reproductive age and combine this with advances in diagnostics that enable self-sampling for STIs at home. ${ }^{56}$

Online services may address barriers to clinic use such as long waiting times, inconvenient opening hours, perceived stigma and travel time or cost. ${ }^{78}$ A recent randomised controlled trial (RCT) demonstrated that when online services are promoted in the community alongside clinic services they increase uptake of STI testing across all population subgroups. ${ }^{9}$ These services may be especially important to some higher-risk populations including young people, black and minority ethnic groups (BME) and men who have sex with men (MSM). ${ }^{810-12}$ One UK study of an online HIV testing service described higher return rates among BME and MSM, suggesting that these services could improve access for these groups. ${ }^{13}$

Online services may also create new barriers to testing through user's concerns about the privacy of online service use, their ability to take the sample correctly and test accuracy. ${ }^{1012} 14$ Barriers of this sort may impact not only ordering of an online test but also on completion and returning of the test. One online service in the USA reported only $31 \%$ of self-sampling kits returned for testing. ${ }^{15}$

Little is known about who uses online services outside of research contexts. This exploratory, cross-sectional study compares the characteristics of those completing an STI test using an online service for STI self-sampling at home to those using clinic services in the two neighbouring south London boroughs of Lambeth and Southwark. Second, it compares the characteristics of those who ordered a test from online services and returned it to those who ordered a test and did not return a sample to identify potential barriers to online service use.

\section{METHODS}

\section{Study setting}

The London boroughs of Lambeth and Southwark are densely populated and ethnically diverse with high levels of deprivation. ${ }^{16} 17$ In 2016, rates of STIs in these boroughs were some of the highest in the country. ${ }^{18}$ New diagnoses of STIs (excluding chlamydia in under 25s) in Lambeth (3288/100 000) and Southwark (2799/100 000) were more than three times the national rate $(795 / 100000)$ and higher than the London regional rate $(1547 / 100000) .{ }^{18}$ 
Similarly, chlamydia detection rates (in people aged $16-25$ years) in Lambeth (4938/100 000) and Southwark (4041/100 000) were twice as high as national $(1882 / 100000)$ and regional rates $(2309 / 100000)^{18}$

In 2016, 13 sexual health services that were open access and free at the point of use served these areas. In addition, free STI testing was available as part of the National Chlamydia Screening Programme (NCSP) to people aged 15-25 years in GPs, although only $5.9 \%$ of chlamydia testing for the NCSP was carried out in GP services. ${ }^{19}$

\section{The online service}

From March 2015, an online service for STI self-sampling at home was made available free of charge to residents of Lambeth and Southwark aged $\geq 16$ years via the SH:24 website (www. sh24.org). SH:24 was promoted using cards and posters in clinic services. At the time of this study, clinic staff were not advising clinic attendees to access online services for basic STI testing. Users of the online service ordered a self-sampling kit for HIV, syphilis, gonorrhoea and chlamydia from the website which was sent to them by post to self-sample at home and return samples to the laboratory in a prepaid envelope. The self-sampling kit included urine sample collection pots, vaginal, rectal and oral swabs and a lancet for finger-prick blood collection. The type of testing kit that the online service user received was tailored to gender and sexual orientation. Support was available remotely via telephone and text message.
At the time of the study, the clinical pathway for treatment and partner notification (PN) in the online service did not differ from clinic services. Test results for chlamydia and gonorrhoea were sent to users via text message, and users were referred to clinics for treatment and PN if necessary. Users reactive for HIV or syphilis were telephoned and referred to clinic services for confirmatory testing, treatment and PN; otherwise, those users testing negative were informed by text.

\section{Study population}

Sexual health service activity data from 1 January 2016 to 31 March 2016 were obtained via electronic transfer from sexual health clinics in the boroughs and combined with service activity data from the online service $\mathrm{SH}: 24$ (figure 1). These data are routinely generated by clinics in the form of the Genitourinary Medicine Clinical Activity dataset (GUMCAD) for monitoring by Public Health England (PHE). Data provided were produced in accordance with GUMCADv2 Technical Guidance. ${ }^{20}$

\section{Inclusion and exclusion criteria}

Data were included for residents of Lambeth and Southwark with Sexual Health \& HIV Activity Property Type (SHHAPT) codes for testing for HIV, syphilis, chlamydia or gonorrhoea, or any combination of these four tests (codes provided in online supplementary material). ${ }^{20}$ We excluded testing activity that was accompanied by activity codes that could not have been carried out using the online service. We excluded testing activity

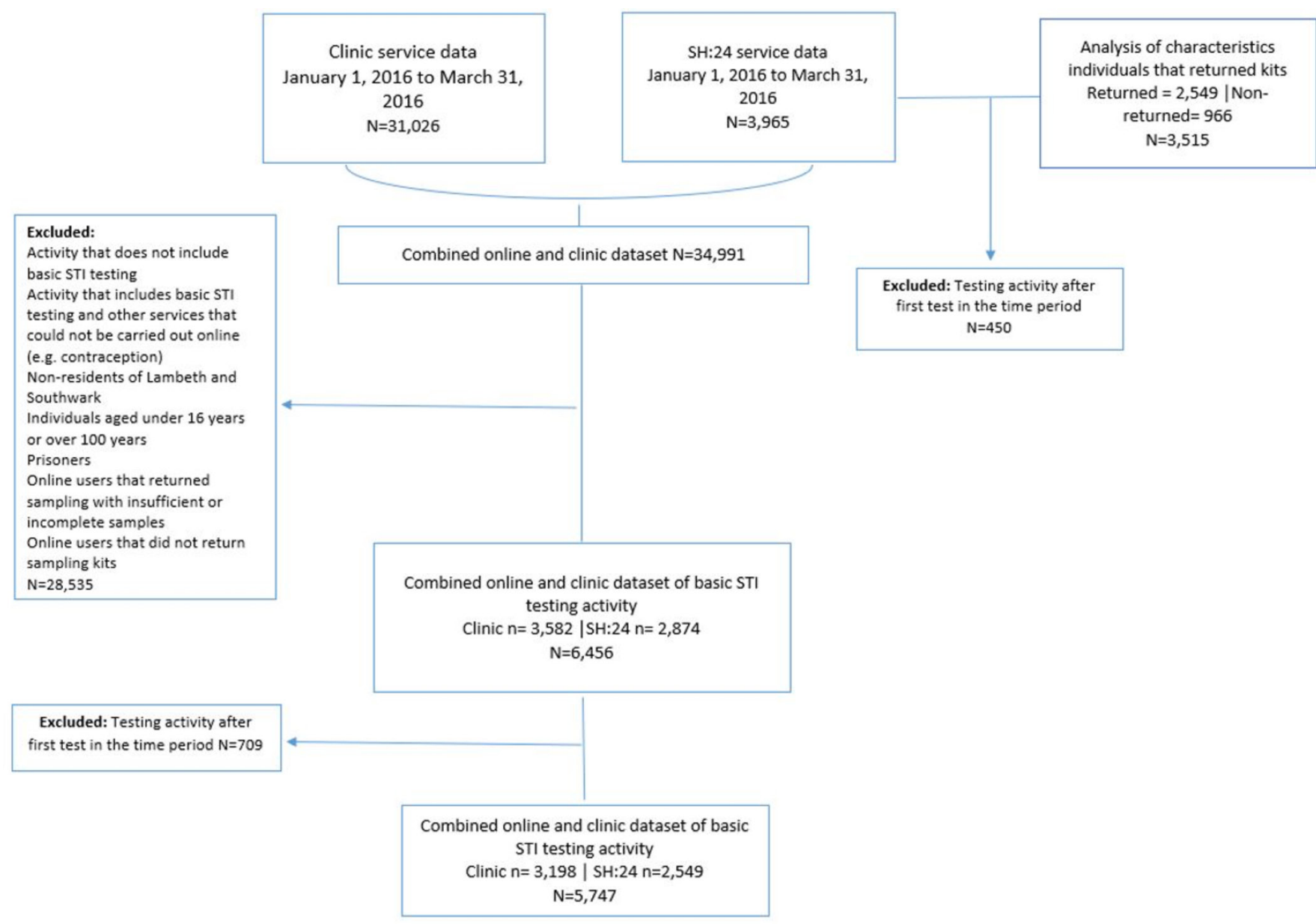

Figure 1 Study flow chart. 
from prisoners because clinic access was not available to prisoners. We restricted covariate analysis to include only an individual's first test within the time period.

Our main analysis compared those who completed a test using the online service and those who completed a test using the clinic services. We excluded data for online users that did not return the sample for testing and samples that were returned but were insufficient to test. Any individual who returned at least one sample for testing that was sufficient to test within 6 weeks of ordering the test was considered as having completed a test (returner). Any individual who did not return any sample for testing within 6 weeks or an individual who returned only insufficient samples for testing was considered as not having completed a test (non-returner).

For the analysis of online services, we compared those that were returners with non-returners. Figure 1 shows a flow chart of how the datasets were generated for analysis and exclusion criteria.

\section{Outcomes}

The outcome variable for type of service use was derived from the dataset of origin. Data from clinic services were combined to create a 'clinic users' category while data from SH:24 service formed the 'online users' category. For the analysis of online service users, we defined online testing service users as returners or non-returners.

\section{Covariates}

Age was measured in 5 -year intervals 16 to $<20,20$ to $<25$, 25 to $<30,30$ to $<35$ and $35+$ years for ease of interpretation. We derived an ethnic group variable with the aim of generating fewer categories while representing the largest ethnic groups in the boroughs. We also considered Index of Multiple Deprivation (IMD) quintiles at Lower Super Output Area level . Gender and sexual orientation are presented as they were reported. We included data for positive test results for chlamydia and gonorrhoea diagnoses as any activity with a SHHAPT code "C4" and/ or "B". Data for reactive results for HIV and syphilis tests were not included in the analysis because at the time of the study reactive results for HIV and syphilis were subsequently retested and confirmed in clinic services.

\section{Statistical analysis}

Descriptive statistics were carried out using non-parametric tests. Unadjusted logistic regression models were used to explore potential associations between type of service use (clinic vs online) and age group, gender, ethnic group, sexual orientation and IMD quintiles. We then used logistic regression models to examine the strength of these associations, controlling for confounding. To avoid an excess number of variables and unstable estimates in our models, only variables with a $\mathrm{P}$ value of $<0.1$ were retained. ${ }^{21}$ The effect of age group, gender, ethnic group, sexual orientation and IMD quintile on online service use was assessed for effect modification using two-way interaction terms within regression models. To investigate the factors influencing sample return among those accessing online services, we used the same methods to explore the association between return of kits (returners vs non-returners) and age group, gender, ethnic group, sexual orientation and IMD quintile. Data were incomplete for only $21(0.4 \%)$ observations; therefore, complete case analysis was carried out. All analyses were conducted with the use of STATA V.14.1 (StataCorp).
RESULTS

\section{Comparing users of online services with users of clinic services among STI testers}

A total of 6456 STI tests were conducted among residents of Lambeth and Southwark between 1 January 2016 and 31 March 2016; $3582(55.5 \%)$ in clinics and $2874(44.5 \%)$ through the online service. In clinics, 384 (10.7\%) individuals were tested on two or more occasions, whereas in the online service the equivalent number was $449(11.3 \%)$. The total number of unique individuals that used online or clinic services for STI testing was $5747,3258(56.7 \%)$ of whom were female. Individuals were aged between 16 and 85 years (median $=27$; IQR $=23-32$ ). The proportion of those testing positive for chlamydia or gonorrhoea was higher among those testing in the clinic (14.4\%) compared with the online service (4.4\%). Descriptive statistics are presented in table 1 .

Users aged between 20 and 30 years were more likely to use online services compared with both younger people and people aged $>35$ years. Women were more likely to use online services compared with men (adjusted OR (adjOR) 1.85, 95\% CI 1.63 to 2.10 ). Those who used online services were more likely to be white British than any other ethnic group. Homosexual and bisexual users were more likely to use the online service compared with heterosexual users, although people reporting their sexual orientation as unknown were also less likely to use online services than the clinic service (adjOR $0.36,95 \%$ CI 0.24 to 0.54 ). Those that tested positive for chlamydia or gonorrhoea were less likely use the online service compared with the clinic service (adjOR 0.30, 95\% CI 0.24 to 0.38). Residents of areas with a higher IMD quintile (less deprived) were more likely to use online services (adjOR 1.06, 95\% CI 1.02 to 1.10). Crude and adjORs are presented in table 2 .

We found evidence that gender modified the effect of ethnicity $(\mathrm{P}=0.006)$ as well as the effect of sexual orientation on service use $(\mathrm{P}=0.017)$; therefore, multivariate analysis is presented stratified by gender (table 2). Among women, being mixed white black African or Caribbean was not significantly associated with lower odds of using online services, while this was the case for men (adjOR 0.51, 95\% CI 0.30 to 0.86). Among women, being homosexual increased the likelihood of online service use (adjOR 5.05, 95\% CI 2.55 to 10.00) more than it did for men (adjOR $1.83,95 \%$ CI 1.45 to 2.31 ).

\section{Comparing returners and non-returners among users of the online service}

In the analysis of the online service, of the 3515 individuals who ordered a kit from the online service, $2549(72.5 \%)$ returned a sufficient sample to the laboratory. Descriptive statistics are presented in table 3. In multivariate analysis, age group and ethnic group were associated with returning a sample. Those most likely to return a sample were aged $>20$ years $(\mathrm{P}<0.05)$. Compared with white British individuals, black African (adjOR 0.70, 95\% CI 0.50 to 0.98), mixed white black African or Caribbean (adjOR 0.64, 95\% CI 0.47 to 0.88 ), any other ethnic group (adjOR $0.58,95 \%$ CI 0.44 to 0.76 ) and those that did not state their ethnic group (adjOR $0.50,95 \%$ CI 0.28 to 0.91 ) were less likely to return a sample for testing. Crude and adjORs of returning a sample are presented in table 3 .

\section{DISCUSSION}

Uptake of online services was high, with $44.5 \%$ of all basic STI testing being carried out online. However, we show differential use of online services for STI self-sampling at home between 
Table 1 Socio-demographic characteristics of individuals who tested for STIs in clinics and through online services in Lambeth and Southwark between 1 January and 31 March $2016(n=5747)$

\begin{tabular}{|c|c|c|c|c|}
\hline Exposure variable & Clinic users, n (\%) & Online users, n (\%) & Total users (\%) & $P$ value $\left(X^{2}\right)$ \\
\hline \multicolumn{5}{|l|}{ Age group (years) } \\
\hline $16-20$ & $257(8.0)$ & $101(4.0)$ & $358(6.2)$ & \multirow[t]{5}{*}{$<0.001$} \\
\hline $20-25$ & $746(23.3)$ & $770(30.2)$ & $1516(26.4)$ & \\
\hline $25-30$ & $844(26.4)$ & $954(37.4)$ & $1798(31.3)$ & \\
\hline $30-35$ & $500(15.6)$ & $395(15.5)$ & $895(15.6)$ & \\
\hline $35+$ & $851(26.6)$ & $329(12.9)$ & $1180(20.5)$ & \\
\hline \multicolumn{5}{|l|}{ Gender } \\
\hline Male & $1578(49.3)$ & $911(35.7)$ & $2489(43.3)$ & \multirow[t]{2}{*}{$<0.001$} \\
\hline Female & $1620(50.7)$ & $1638(64.3)$ & $3258(56.7)$ & \\
\hline \multicolumn{5}{|l|}{ Ethnic group } \\
\hline White British & $751(23.5)$ & $1482(58.3)$ & $2233(38.9)$ & \multirow[t]{9}{*}{$<0.001$} \\
\hline White other & $505(15.8)$ & $324(12.7)$ & $829(14.4)$ & \\
\hline Black African & $444(13.9)$ & $116(4.6)$ & $560(9.7)$ & \\
\hline Black Caribbean & $314(9.8)$ & $166(6.5)$ & $480(8.4)$ & \\
\hline Black other & $399(12.5)$ & $97(3.8)$ & $496(8.6)$ & \\
\hline Mixed white black African or Caribbean & $101(3.2)$ & $124(4.9)$ & $225(3.9)$ & \\
\hline South Asian & $54(1.7)$ & $36(1.4)$ & $90(1.6)$ & \\
\hline Any other ethnic group & $430(13.5)$ & $170(6.7)$ & $600(10.4)$ & \\
\hline Not stated & $200(6.3)$ & $29(1.1)$ & $229(5.2)$ & \\
\hline \multicolumn{5}{|l|}{ Sexual orientation } \\
\hline Heterosexual & $2648(82.8)$ & $2083(81.7)$ & $4731(82.3)$ & \multirow[t]{4}{*}{$<0.001$} \\
\hline Homosexual & $319(10.0)$ & $332(13.0)$ & $651(11.3)$ & \\
\hline Bisexual & $65(2.0)$ & $100(3.9)$ & $165(2.9)$ & \\
\hline Unknown & $166(5.2)$ & $34(1.3)$ & $200(2.5)$ & \\
\hline Tested positive for chlamydia or gonorrhoea & $461(14.4)$ & $111(4.4)$ & $572(10.0)$ & $<0.001$ \\
\hline \multicolumn{5}{|l|}{ IMD quintile } \\
\hline 1 (most deprived) & $1324(41.5)$ & $791(31.1)$ & $2115(36.8)$ & \multirow[t]{5}{*}{$<0.001$} \\
\hline 2 & $1272(39.9)$ & $1122(44.2)$ & $2394(41.7)$ & \\
\hline 3 & $480(15.1)$ & $494(19.4)$ & $974(17.0)$ & \\
\hline 4 & $102(3.2)$ & $117(4.6)$ & $219(3.8)$ & \\
\hline 5 (least deprived) & $12(0.4)$ & $17(0.7)$ & $29(0.5)$ & \\
\hline Total & $3198(55.7)$ & $2549(44.3)$ & 5747 & \\
\hline
\end{tabular}

Missing data for 16 observations for IMD and 8 observations for ethnic group.

IMD, Index of Multiple Deprivation.

socio-demographic groups. Some higher-risk groups including young people aged between 20 and 25 years and MSM used online services. Other higher-risk groups including young people aged between 16 and 20 years and BME groups were more likely to use clinic services for STI testing than online services, and there are lower levels of positive diagnoses of chlamydia and gonorrhoea seen in users of the online service. Among individuals who ordered a self-sampling kit from the online service, those most likely to return kits for testing were aged $>20$ years and white British.

To our knowledge, this is the first study to compare individual-level data from clinic and online sexual health services for STI testing to identify key socio-demographic factors associated with online service use in a real-world setting. The main strengths of our study are that the sample size is large and that we consulted clinicians from local services as well as external academics to define outcome variables. However, there are some weaknesses. Our dataset does not include data from STI testing in GPs, so we are limited to comparing online users with sexual health clinic users. Surveillance data do not contain unique identifiers; therefore, we are unable to link treatment of positive cases in clinics to testing for online service users. Additionally, in the online service and two of the clinic services, users reported their characteristics via computer terminals while other services used face-to-face interviewing. This may have led to a reduction in the reporting of characteristics more sensitive to stigma such as sexual orientation and ethnic group clinic services, resulting in an underestimation of use of clinic services among bisexual and homosexual individuals and for BME groups. ${ }^{22}$

Few studies have compared the characteristics of online users to clinic users. Two RCTs investigated the effectiveness of online services on uptake of testing, both report similarities in the characteristics of online users and clinic users. ${ }^{92}$ In the UK, an RCT investigating the same online service as our study ( $\mathrm{SH}: 24)$ reported no differences in uptake between socio-demographic groups. This study reported a reduction in time to test but not time to treatment in the online arm and good follow-up (84\%); however, it lacked power to detect differences in STI diagnoses between online and clinic arms. ${ }^{9}$ In France, an RCT investigating an intervention to encourage chlamydia testing via an online service on uptake of testing suggested the intervention had a greater effect on men, though no other differences in the uptake between groups were observed. ${ }^{23}$ However, this may be subject to bias due to low follow-up (30\%). ${ }^{23}$ 
Table 2 Crude and adjusted ORs of use of online services compared with use of clinic services for STI testing in Lambeth and Southwark by age group, gender, ethnic group, sexual orientation, positivity and stratified by gender

\begin{tabular}{|c|c|c|c|c|}
\hline \multirow[b]{2}{*}{ Exposure variable } & \multicolumn{2}{|c|}{ Total population $(n=5726)$} & \multirow{2}{*}{$\begin{array}{l}\text { Men only }(n=2481) \\
\text { Adjusted OR } ¥(95 \% \mathrm{Cl})\end{array}$} & \multirow{2}{*}{$\begin{array}{l}\text { Women only }(\mathrm{n}=3245) \\
\text { Adjusted OR }(95 \% \mathrm{Cl})\end{array}$} \\
\hline & Crude OR $(95 \% \mathrm{Cl})$ & Adjusted OR $(95 \% \mathrm{Cl}) \dagger$ & & \\
\hline \multicolumn{5}{|l|}{ Age group (years) } \\
\hline $16-20$ & 1 (ref) & 1 (ref) & 1 (ref) & 1 (ref) \\
\hline $20-25$ & $2.63^{* *}(2.04$ to 3.38$)$ & $2.11^{* *}(1.77$ to 3.08$)$ & $1.71 *$ (1.00 to 2.94$)$ & $2.42^{* *}(1.73$ to 3.39$)$ \\
\hline $25-30$ & $2.88^{* *}(2.24$ to 3.69$)$ & $2.33^{* *}(2.03$ to 3.50$)$ & $2.10 *(1.24$ to 3.56$)$ & $2.45^{* *}(1.75$ to 3.43$)$ \\
\hline $30-35$ & $2.01^{* *}$ (1.54 to 2.62$)$ & $1.65^{* *}(1.43$ to 2.57$)$ & 1.47 (0.85 to 2.54$)$ & 1.77 (1.23 to 2.56$)$ \\
\hline $35+$ & $0.98(0.76$ to 1.28$)$ & $0.88(0.78$ to 1.39$)$ & $0.81(0.47$ to 1.39$)$ & 0.91 (0.63 to 1.32$)$ \\
\hline \multicolumn{5}{|l|}{ Gender } \\
\hline Male & 1 (ref) & 1 (ref) & - & - \\
\hline Female & $1.75^{* *}(1.57$ to 1.95$)$ & $1.82^{* *}(1.63$ to 2.10$)$ & - & - \\
\hline \multicolumn{5}{|l|}{ Ethnic group } \\
\hline White British & 1 (ref) & 1 (ref) & 1 (ref) & 1 (ref) \\
\hline White other & $0.33^{* *}(0.28$ to 0.38$)$ & $0.34^{* *}(0.29$ to 0.41$)$ & $0.36^{* *}(0.28$ to 0.48$)$ & $0.34^{* *}(0.27$ to 0.42$)$ \\
\hline Black African & $0.13^{* *}(0.11$ to 0.17$)$ & $0.18^{* *}(0.15$ to 0.23$)$ & $0.17^{* *}(0.12$ to 0.24$)$ & $0.19 * *(0.14$ to 0.26$)$ \\
\hline Black Caribbean & $0.27^{* *}(0.22$ to 0.33$)$ & $0.36^{* *}(0.29$ to 0.45$)$ & $0.26^{* *}(0.18$ to 0.37$)$ & $0.44^{* *}(0.33$ to 0.58$)$ \\
\hline Black other & $0.12^{* *}(0.98$ to 0.16$)$ & $0.16^{* *}(0.12$ to 0.20$)$ & $0.09 * *(0.06$ to 0.15$)$ & $0.21^{* *}(0.15$ to 0.29$)$ \\
\hline $\begin{array}{l}\text { Mixed white black African or } \\
\text { Caribbean }\end{array}$ & $0.62 *(0.47$ to 0.82$)$ & $0.71 *(0.53$ to 0.95$)$ & $0.51 *(0.30$ to 0.86$)$ & 0.83 (0.58 to 1.19$)$ \\
\hline South Asian & $0.34^{* *}(0.22$ to 0.52$)$ & $0.41^{* *}(0.26$ to 0.65$)$ & $0.51 *(0.27$ to 0.93$)$ & $0.32^{* *}(0.17$ to 0.62$)$ \\
\hline Any other ethnic group & $0.20 * *(0.16$ to 0.24$)$ & $0.22^{* *}(0.18$ to 0.27$)$ & $0.26^{* *}(0.19$ to 0.36$)$ & $0.20 * *(0.15$ to 0.26$)$ \\
\hline Not stated & $0.07^{* *}(0.50$ to 0.11$)$ & $0.09 * *(0.06$ to 0.13$)$ & $0.06^{* *}(0.03$ to 0.14$)$ & $0.10 * *(0.06$ to 0.17$)$ \\
\hline \multicolumn{5}{|l|}{ Sexual orientation } \\
\hline Heterosexual & 1 (ref) & 1 (ref) & 1 (ref) & 1 (ref) \\
\hline Homosexual & $1.32 *(1.12$ to 1.56$)$ & $2.23^{* *}(1.81$ to 2.74$)$ & $1.83^{* *}(1.45$ to 2.31$)$ & $5.05^{* *}(2.55$ to 10.00$)$ \\
\hline Bisexual & $1.96^{* *}$ (1.42 to 2.69$)$ & $2.10^{* *}(1.47$ to 3.01$)$ & $2.23^{*}(1.28$ to 3.87$)$ & $1.90 *(1.20$ to 3.04$)$ \\
\hline Unknown & $0.26^{* *}(0.18$ to 0.38$)$ & $0.36^{* *}(0.24$ to 0.55$)$ & $0.46^{*}(0.23$ to 0.93$)$ & $0.33^{* *}(0.20$ to 0.54$)$ \\
\hline \multicolumn{5}{|l|}{$\begin{array}{l}\text { Tested positive for chlamydia or } \\
\text { gonorrhoea }\end{array}$} \\
\hline No & 1 (ref) & 1 (ref) & 1 (ref) & 1 (ref) \\
\hline Yes & $0.27^{* *}(0.22$ to 0.33$)$ & $0.30 * *(0.24$ to 0.38$)$ & $0.35^{* *}(0.25$ to 0.49$)$ & $0.26^{* *}(0.19$ to 0.37$)$ \\
\hline IMD quintile & $1.29 * *(1.21$ to 1.37$)$ & $1.09 *(1.02$ to 1.17$)$ & $1.12^{*}(1.00$ to 1.24$)$ & 1.07 (0.98 to 1.18$)$ \\
\hline
\end{tabular}

Missing data for 16 observations for IMD and 8 observations for ethnic group. Missing data excluded from multivariate analysis.

IMD quintile range $1=5$, where $1=$ most deprived and $5=$ least deprived entered into the model as a continuous variable (base $=1$ ).

${ }^{*} \mathrm{P} \leq 0.05,{ }^{*} \mathrm{P} \leq 0.001$.

†Adjusted for age group, gender, ethnic group, sexual orientation, IMD quintile, tested positive for chlamydia or gonorrhoea.

$¥$ Adjusted for age group, ethnic group, sexual orientation, IMD quintile, tested positive for chlamydia or gonorrhoea.

IMD, Index of Multiple Deprivation.

Other observational studies in the UK, the USA, France and Sweden have described characteristics of users of online services for self-sampling at home. ${ }^{13152425}$ An observational study linked to the French RCT reported similar findings to our study. ${ }^{26}$ In Sweden, a similar online service saw $74.5 \%$ of kits returned by a majority of female users and young people aged $<25$ years. $^{25}$ Studies in the UK and the USA have reported high use of online services among BME, low-income groups and MSM and high positivity, but lower return rates. ${ }^{13} 1524$ While there are some similarities in these results, any differences may be a result of a variation in context, for example, the US studies evaluated service that was free of charge to users within a predominantly private medical context.

Differences in findings between trials and observational studies may reflect the equitable information that trial participants receive, irrespective of their socio-demographic characteristics. In real-world settings, some groups may have less information about services than others, which could result in differential uptake between groups. ${ }^{9}$ These differences may also reflect that the French RCT recruited all participants online and the UK trial recruited 54\% of participants online; therefore, both trial populations may have higher levels of acceptance of online services. ${ }^{9}$

We have demonstrated that barriers to online service use exist both before someone orders a self-sampling kit and during the process of self-sampling and returning of kits; however, we are unable to determine what the barriers are. Qualitative studies have highlighted possible barriers to use of online services among potential service users. These include concerns about concealment of service use that involves receiving a package at home or a message on mobile phones, data security, need for professional support during sampling and accuracy of the test. ${ }^{102728}$ These concerns may be particularly important for young people ${ }^{10}$ and BME groups. ${ }^{27}$ Additionally, potential concerns about ability to use the kit correctly have been reported as a barrier to self-sampling. ${ }^{1027}$ These qualitative studies give some indication of what the barriers to online STI testing could be, although they investigate hypothetical responses to a potential intervention.

PHE recommends that innovations for STI testing should aim to increase access to STI testing among groups at higher risk 
Table 3 Number, proportion and determinants of returning self-sampling kits among users of online services for self-sampling for STIs at home

\begin{tabular}{|c|c|c|c|c|}
\hline Exposure variable & Unreturned kits, n (\%) & Returned kits, n (\%) & $\begin{array}{l}\text { Crude OR }(95 \% \mathrm{Cl}) \\
\mathrm{n}=3964\end{array}$ & $\begin{array}{l}\text { Adjusted ORT }(95 \% \mathrm{Cl}) \\
\mathrm{n}=3947\end{array}$ \\
\hline \multicolumn{5}{|l|}{ Age group (years) } \\
\hline $16-20$ & $71(7.4)$ & $101(4.0)$ & 1 (ref) & 1 (ref) \\
\hline $20-25$ & $294(30.4)$ & $770(30.2)$ & $1.84^{* *}$ (1.32 to 2.57$)$ & $1.68^{*}(1.20$ to 2.36$)$ \\
\hline $25-30$ & $340(35.2)$ & $954(37.4)$ & $1.97^{* *}$ (1.42 to 2.47$)$ & $1.81^{*}$ (1.29 to 2.54$)$ \\
\hline $30-35$ & $128(13.3)$ & $395(15.5)$ & $2.17^{* *}$ (1.51 to 3.12 ) & $2.03^{* *}$ (1.40 to 2.94$)$ \\
\hline $35+$ & $133(13.8)$ & $329(12.9)$ & $1.74^{*}(1.21$ to 2.50$)$ & $1.66^{*}(1.14$ to 2.42$)$ \\
\hline \multicolumn{5}{|l|}{ Gender } \\
\hline Male & $374(38.7)$ & $911(35.7)$ & 1 (ref) & 1 (ref) \\
\hline Female & $592(61.3)$ & $1638(64.3)$ & 1.14 (0.98 to 1.32 ) & 1.18 (1.00 to 0.39$)$ \\
\hline \multicolumn{5}{|l|}{ Ethnic group } \\
\hline White British & $488(50.6)$ & $1482(58.3)$ & 1 (ref) & 1 (ref) \\
\hline White other & $111(11.5)$ & $324(12.7)$ & 0.96 (0.76 to 1.22$)$ & 0.95 (0.75 to 1.21$)$ \\
\hline Black African & $58(6.0)$ & $116(4.6)$ & $0.66^{*}(0.47$ to 0.92$)$ & $0.70 *(0.50$ to 0.98$)$ \\
\hline Black Caribbean & $69(7.2)$ & $166(6.5)$ & 0.79 (0.59 to 1.07 ) & 0.84 (0.62 to 1.13 ) \\
\hline Black other & $37(3.8)$ & $97(3.8)$ & 0.86 (0.58 to 1.28$)$ & 0.92 (0.62 to 1.36 ) \\
\hline $\begin{array}{l}\text { Mixed white black African or } \\
\text { Caribbean }\end{array}$ & $68(7.1)$ & $124(4.9)$ & $0.60^{*}(0.44$ to 0.82$)$ & $0.64^{*}(0.47$ to 0.88$)$ \\
\hline South Asian & $14(1.5)$ & $36(1.4)$ & 0.85 (0.45 to 1.58$)$ & 0.93 (0.49 to 1.74$)$ \\
\hline Any other ethnic group & $100(10.4)$ & $170(6.7)$ & $0.56^{* *}$ ( 0.53 to 0.73$)$ & $0.58^{* *}(0.44$ to 0.76$)$ \\
\hline Not stated & $19(2.0)$ & $29(1.1)$ & $0.50^{*}(0.28$ to 0.90$)$ & $0.50^{*}(0.28$ to 0.91$)$ \\
\hline \multicolumn{5}{|l|}{ Sexual orientation } \\
\hline Heterosexual & $777(80.4)$ & $2083(81.7)$ & 1 (ref) & 1 (ref) \\
\hline Homosexual & $123(12.7)$ & $332(13.0)$ & 1.01 (0.81 to 1.26 ) & 1.06 (0.83 to 1.36 ) \\
\hline Bisexual & $40(4.1)$ & $100(3.9)$ & 0.93 (0.64 to 1.36 ) & 0.96 (0.65 to 1.40$)$ \\
\hline Not stated/not known & $26(2.7)$ & $34(1.3)$ & $0.49^{*}(0.29$ to 0.82$)$ & $0.53^{*}(0.31$ to 0.89$)$ \\
\hline \multicolumn{5}{|l|}{ IMD quintile } \\
\hline 1 (most deprived) & $325(33.8)$ & $791(31.1)$ & 1 (ref) & - \\
\hline 2 & $418(43.4)$ & $1122(44.2)$ & 1.10 (0.93 to 1.31$)$ & - \\
\hline 3 & $186(19.3)$ & $494(19.4)$ & 1.09 (0.88 to 1.35$)$ & - \\
\hline 4 & $29(3.0)$ & $117(4.6)$ & $1.66^{*}$ (1.08 to 2.54$)$ & - \\
\hline 5 (least deprived) & $5(0.5)$ & $17(0.7)$ & 1.40 (0.51 to 3.81 ) & - \\
\hline Total & $966(27.5)$ & $2549(72.5)$ & & \\
\hline
\end{tabular}

Missing data for 11 observations for IMD and 7 observations for ethnic group. Missing data excluded from multivariate analysis.

${ }^{*} \mathrm{P}<0.05,{ }^{* *} \mathrm{P}<0.001$

†Adjusted for age group, gender, ethnic group and sexual orientation.

IMD, Index of Multiple Deprivation.

of infection. ${ }^{27}$ Evidence from our study suggests that at this early stage of service implementation online services are used less by some higher-risk groups. This may reflect barriers to service use, including differential information between groups. However, differences could be a result of appropriate service use, for example, when additional services are being sought which are not available online, such as human papillomavirus or hepatitis B vaccination for MSM. ${ }^{28}$ Lower diagnoses among online service users may reflect appropriate signposting from online services, advising symptomatic users to attend clinics for testing.

At this early stage of service provision, the evidence suggests that when online services for STI self-sampling are made available as part of routine service provision, use is lower among some important higher-risk groups and positive diagnoses are lower in online services. Barriers to accessing online services may exist for users at the point of ordering the test or at the point of taking the sample. Existing qualitative literature examining what these barriers are is limited because it investigates barriers with potential service users, rather than actual service users. As online sexual health services increasingly become a first point of access, it is important to further understand the barriers to access and how they are experienced by different socio-demographic groups. This information will underpin development of online services that are more widely accessible or alternatives for those who prefer not to use online services. This paper informs future efforts in this direction.

\section{Key messages}

- Almost half of all basic STI testing is being done online, although there is differential use between socio-demographic groups.

- The rate of positive diagnoses is lower in online services compared with clinics, although this may be appropriate as symptomatic cases are signposted to clinics.

- Understanding barriers to using online services for STI selfsampling at home could inform the provision of support or alternatives.

- Clinics remain an important point of access for some higherrisk groups (black and minority ethnic groups, 16-20s) while online services are an important point of access for others (20-30s). 
Handling editor Jackie A Cassell

Acknowledgements KJL and KMET thank the National Institute for Health Research Health Protection Research Unit (NIHR HPRU) in Evaluation of Interventions at the University of Bristol, in partnership with Public Health England (PHE), for research support. The work of SB, IB, KMET, KJL, CF and PB on this study was funded from a grant from Guys and St Thomas' Charity for the evaluation of $\mathrm{SH}: 24$ which is part of a grant funding the development of the $\mathrm{SH}: 24$ online service.

Contributors SB, PB and CF conceived the study. SB, PB, CF and IB contributed to the study design, literature search, data management, data analysis, data interpretation and writing of the manuscript. PB, CF and IB are co-supervisors of SB. KJL contributed to the data management, data interpretation and writing of the manuscript. KMET contributed to the data management and writing of the manuscript. SB and PB had full access to the data and had final responsibility for the decision to submit for publication.

Funding This study was funded by the Guys and St Thomas' Charity as part of a larger evaluation of the $\mathrm{SH}: 24$ online sexual health service. The research by IB is supported by the National Institute for Health Research (NIHR) Biomedical Research Centre at South London and Maudsley NHS Foundation Trust and by the National Institute for Health Research (NIHR) Collaboration for Leadership in Applied Health Research and Care South London at King's College Hospital NHS Foundation Trust, King's College London.

Disclaimer The views expressed are those of the authors and not necessarily those of the National Health Service, the NIHR, the Department of Health or Public Health England.

Competing interests $\mathrm{PB}$ is a director of $\mathrm{SH}: 24$.

Ethics approval Ethical approval was obtained from the NRES Committee North of Scotland, Grampian (Ref 15/NS/0031).

Provenance and peer review Not commissioned; externally peer reviewed.

Open access This is an open access article distributed in accordance with the Creative Commons Attribution Non Commercial (CC BY-NC 4.0) license, which permits others to distribute, remix, adapt, build upon this work non-commercially, and license their derivative works on different terms, provided the original work is properly cited and the use is non-commercial. See: http://creativecommons.org/ licenses/by-nc/4.0/

(c) Article author(s) (or their employer(s) unless otherwise stated in the text of the article) 2018. All rights reserved. No commercial use is permitted unless otherwise expressly granted.

\section{REFERENCES}

1 Public Health England. Infection Report HIV-STIs. London: Public Health England, 2016

2 Public Health England. HIV in the United Kingdom. London: Public Health England, 2016

3 Dallabetta G, Wi T, Nielsen G, et al. Prevention and control of STD and HIV infection in developing countries. Sexually transmitted diseases. 4th edn. New York, NY: McGrawHill, 2008.

4 Public Health England. Health promotion for sexual and reproductive health and HIV: strategic action plan, 2016 to 2019. London: Public Health England, 2015.

5 Office for National Statistics. Internet users in the UK: 2016. UK: ONS, 2016. https://www.ons.gov.uk/businessindustryandtrade/itandinternetindustry/bulletins/ internetusers/2016.

6 Odesanmi TY, Wasti SP, Odesanmi OS, et al. Comparative effectiveness and acceptability of home-based and clinic-based sampling methods for sexually transmissible infections screening in females aged $14-50$ years: a systematic review and meta-analysis. Sex Health 2013;10:559-69.

7 Fortenberry JD, McFarlane M, Bleakley A, et al. Relationships of stigma and shame to gonorrhea and HIV screening. Am J Public Health 2002:92:378-81.

8 Lorimer K, McDaid L. Young men's views toward the barriers and facilitators of Internet-based Chlamydia trachomatis screening: qualitative study. J Med Internet Res 2013;15:e265

9 Wilson E, Free C, Morris TP, et al. Internet-accessed sexually transmitted infection (e-STI) testing and results service: a randomised, single-blind, controlled trial. PLOS Med 2017;14.

10 Aicken CR, Fuller SS, Sutcliffe LJ, et al. Young people's perceptions of smartphoneenabled self-testing and online care for sexually transmitted infections: qualitative interview study. BMC Public Health 2016;16:974.

11 Witzel TC, Rodger AJ, Burns FM, et al. HIV Self-Testing among Men Who Have Sex with Men (MSM) in the UK: A Qualitative Study of Barriers and Facilitators, Intervention Preferences and Perceived Impacts. PLoS One 2016;11:e0162713.

12 Powell R, Pattison HM, Francis JJ. An online study combining the constructs from the theory of planned behaviour and protection motivation theory in predicting intention to test for chlamydia in two testing contexts. Psychol Health Med 2016;21:38-51.

13 Guerra LL, Alston L, Gill T, et al. The National HIV Self-Sampling Service. Oxford, UK: British Association of Sexual Health and HIV, 2016.

14 Grispen JE, Ronda G, Dinant GJ, et al. To test or not to test: a cross-sectional survey of the psychosocial determinants of self-testing for cholesterol, glucose, and HIV. BMC Public Health 2011:11:112.

15 Chai SJ, Aumakhan B, Barnes M, et al. Internet-based screening for sexually transmitted infections to reach nonclinic populations in the community: risk factors for infection in men. Sex Transm Dis 2010;37:756-63.

16 Aldridge HB, Kenway S, Maclnnes P, et al. London's Poverty Profile: Southwark. London New Policy Institute and The Trust for London, 2013.

17 Lambeth Council. Lambeth: State of the Borough 2014. London: Lambeth Council, 2014.

18 Public Health England. Public Health Outcomes Framework Sexual and Reporductive Health Profiles. UK: PHE, 2016.

19 Public Health England. Chlamydia testing data for testing service type by region for 15-24 year olds: CTAD, London Public Health England, 2016.

20 Public Health England. GUMCADv2 Technical Guidance and Extract Specification for Data Extract. UK: PHE, 2015.

21 Mickey RM, Greenland S. The impact of confounder selection criteria on effect estimation. Am J Epidemiol 1989:129:125-37.

22 Aspinall PJ. The conceptual basis of ethnic group terminology and classifications. Soc Sci Med 1997:45:689-98.

23 Kersaudy-Rahib D, Lydié N, Leroy C, et al. Chlamyweb Study II: a randomised controlled trial (RCT) of an online offer of home-based Chlamydia trachomatis sampling in France. Sex Transm Infect 2017:93:188-95.

24 Gaydos CA, Dwyer K, Barnes M, et al. Internet-based screening for Chlamydia trachomatis to reach non-clinic populations with mailed self-administered vaginal swabs. Sex Transm Dis 2006;33:451-7.

25 Novak D, Novak M. Use of the Internet for home testing for Chlamydia trachomatis in Sweden: who are the users? Int I STD AIDS 2012;23:83-7.

26 Lydié N, de Barbeyrac B, Bluzat L, et al. Chlamyweb study I: rationale, design and acceptability of an internet-based chlamydia testing intervention. Sex Transm Infect 2017;93:179-87.

27 Frye V, Wilton L, Hirshfied S, et al. "Just because it's out there, people aren't going to use it." HIV Self-testing among young, black MSM, and transgender women. AIDS Patient Care STDS 2015:29:617-24.

28 Gkatzidou V, Hone K, Sutcliffe L, et al. User interface design for mobile-based sexual health interventions for young people: design recommendations from a qualitative study on an online Chlamydia clinical care pathway. BMC Med Inform Decis Mak 2015;15:72. 